\title{
Blanks to be Filled
}

Public-Making and the Censorship of Jia Pingwa's Decadent Capital

\section{Thomas Chen}

\section{(2) OpenEdition \\ Journals}

Electronic version

URL: http://journals.openedition.org/chinaperspectives/6625

DOI: $10.4000 /$ chinaperspectives.6625

ISSN: 1996-4617

\section{Publisher}

Centre d'étude français sur la Chine contemporaine

\section{Printed version}

Date of publication: 1 March 2015

Number of pages: 15-22

ISSN: 2070-3449

\section{Electronic reference}

Thomas Chen, «Blanks to be Filled», China Perspectives [Online], 2015/1 | 2015, Online since 01 January 2017, connection on 28 October 2019. URL : http://journals.openedition.org/ chinaperspectives/6625; DOI : 10.4000/chinaperspectives.6625

(C) All rights reserved 


\title{
Blanks to be Filled
}

\section{Public-Making and the Censorship of Jia Pingwa's Decadent Capital}

\section{THOMAS CHEN}

\begin{abstract}
Jia Pingwa's Decadent Capital was wildly popular upon its publication in 1993. Offering plenty of sex and a bleak view of Chinese society under reform, it was also highly controversial, not least because of the blank squares strewn throughout the text to represent erotic descriptions edited out by the author. Commentators accused Jia of selling out high culture, much like the intellectuals portrayed in the narrative. The novel was banned in 1994 but rereleased in 2009 with one major change: the blank squares were replaced by ellipses. I argue that these blank squares not only make public censorship itself but also constitute the space of alternative publics, whether harking back to an elided past or projecting into a future yet to be written, that the post-Tiananmen Party-state tries to nullify.
\end{abstract}

KEYWORDS: Jia Pingwa, censorship, publishing industry, postsocialism, dystopia, utopia, Tiananmen Square, public, criticism, Lu Xun.

n July 2009 a novel that had been banned for $151 \frac{1}{2}$ years quietly went on sale again. That novel was Jia Pingwa's Fei du (废都), or Decadent Capital. Set in the 1980s in the fictional provincial capital of Xijing (西京), the story follows the celebrated writer Zhuang Zhidie through various extramarital affairs as he battles a lawsuit and tries to finish a novel. The 2009 edition was not the same as the original, however: the 1993 edition possessed a key feature that the new one did not. It was not the sex; that was left untouched. But the blank squares - $\square \square \square \square \square \square$ - followed by "(the author has deleted $n$ characters)" (zuozhe shan qu n zi 作者刪去n字), strewn throughout the 1993 text in place of sexual descriptions edited out by Jia, were replaced in 2009 by ellipses - ..... - and "(here the author has made deletions)" (ci chu zuozhe you shan jie 此处作者有刪节).

The change may seem minor, but this second censorship reveals what is at stake in post-Tiananmen cultural governance: the closure of alternative publics. (1) Decadent Capital, constituted as it was through censorship, nevertheless defies it, as my reading will argue. In this article I first situate the novel in the post-socialist literary landscape from which it emerged in 1993 and analyse its depiction of that very landscape. I then examine the critical discourse surrounding the infamous blank squares, both their appearance in the first edition and their disappearance from the reissue. Finally, by way of a brief consideration of their place in modern Chinese literary history, I contend that the blank squares not only make public censorship itself but also constitute the space of alternative publics, whether harking back to an elided past or projecting into a future yet to be written.

\section{The literary marketplace}

First published amidst a veritable uproar in the summer of 1993, Decadent Capital signalled perhaps more than any other work of the reform period the transformation of the publishing industry that started with marketisation - reduction of state subsidies and purchases, decentralisation, the lifting of controls on prices and resource allocation - in the 1980s and accelerated after Deng Xiaoping's celebrated "southern tour" in 1992. (2) There were rumours (promotional ploy or not) of bidding wars and a million-yuan ad- vance, and more than a dozen publishers vied for the novel before it was even completed. After Beijing Publishing House won the book contract, demand was so high that it sold its printing rights to six other presses. ${ }^{(3)}$ Then in January 1994, the ban was announced. Printing and distribution were stopped, copies were recalled, and not only were the publisher's profits confiscated, it was assessed twice the amount in fines. ${ }^{(4)}$

Speculated on for months - perhaps another ruse to drive up sales - the ban, when it did come, came as no surprise, for the text, marked as it is by

1. I choose "public" over "public sphere," the concept translated into English from Jürgen Habermas's manifold Öffentlichkeit in his seminal The Structural Transformation of the Public Sphere: An Inquiry into a Category of Bourgeois Society, originally published in German in 1962. Ever since the early 1990s, i.e., after 1989 - the year of the English translation of the above work and of the Tiananmen Square protests, U.S.-based scholars have sought to answer questions such as whether China has had a public sphere, whether China will develop one, and whether it is possible or even meaningful to apply the concept to the Chinese context. As "public sphere," in its current usage, is predicated upon the free exchange of rational, critical discourse in a bourgeois society, I find it less suitable for my purposes here than "public."

2. Prior to reform, book prices were set at a standard rate based on the number of sheets used. Distribution was a centralised operation with essentially three routes: books were fed into the state educational system, passed among danwei, or work-units, or sold through the only bookstore in town, the state-run Xinhua Bookstore chain (Virginia Barry, Red - the New Black, China-UK Publishing, London, Arts Council England, 2007, p. 83). Xinhua Bookstore lost its exclusive rights of distribution in 1985. They were briefly reinstated in September 1989 during a campaign against pornography, though apparently books by Zhao Ziyang, Hu Yaobang, Liu Binyan, and Fang Lizhi were also considered dirty (Chen Yi, "Publishing in China in the Post-Mao Era: The Case of Lady Chatterley's Lover," Asian Survey, Vol. 32, No. 6, 1992, pp. 569 and 581; Richard Curt Kraus, The Party and the Arty in China: The New Politics of Culture, Lanham, Rowman \& Littlefield, 2004, p. 93). For an informative account of how much writers were paid in the socialist period, see Perry Link, The Uses of Literature: Life in the Socialist Chinese Literary System, Princeton, Princeton University Press, 2000, pp. 129-133.

3. The literary journal October, also published by the Beijing Publishing House, had been first awarded the periodical contract, which is considered separate under Chinese copyright law.

4. You Mianjin, "Fei du chongban: rang wenxue de gui wenxue" (New edition of Decadent Capital: Let literature belong to literature), Xin jing bao, 30 July 2009, http://culture.people.com.cn/ $\mathrm{GB} / 27296 / 9750065 . \mathrm{html}$ (accessed on 1 April 2014). For the theory that the ban came late so the General Administration of Press and Publication, or GAPP, could profit more from the fines, see Xiao Xialin (ed.), Fei du fei shei (Decadent Capital, decadent who?), Beijing, Xueyuan chubanshe, 1993, p. 112. The then editor of October, Tian Zhenying, a Shaanxi native who had professedly read the manuscript of Decadent Capital nine times in a row and thereby moved jia so much that he gave her the rights, was forced into early retirement (Jiang Wenjuan, "Lao bianji pilu Fei du zao jin neimu: yiyejian tiantang bian diyu" [Former editor discloses the scenes behind Decadent capital's ban: In the blink of an eye heaven becomes hell], Qingnian zhoumo, 6 August 2009, http://media.people.com.cn/GB/40606/9804080.html [accessed on 4 April 2014]). 
manifest instances of self-censorship, still contains a healthy dose of explicit sex, as seen in this scene featuring the protagonist Zhuang Zhidie and one of his mistresses, Tang Wan'er (唐宛儿):

Tang Wan'er was going to take off her shoes and stockings completely, but Zhuang Zhidie said he preferred her with heels, lifted her legs and, standing by the bed, started to do it. $\square \square \square \square \square \square$ (the author has deleted three hundred seventy-nine characters) She was screaming, attached yet in motion. Zhuang Zhidie had never experienced this, and immediately his male desire to conquer bounded. He counted to a hundred and didn't come early, surprising even himself. Tang Wan'er's face had long been flushed, her hair wild, yet she sat up and said: "Let me change positions for you!" She got off the bed and bent over the side. Zhuang Zhidie still didn't come, his eyes fixing on a blue birthmark on her left butt, not saying a word, only hyperventilating. She paused to take off her shoes and stockings, $\square \square \square \square \square \square$ (the author has deleted two hundred thirteen characters) Zhuang Zhidie drunkenly watched her contort like a worm, her lips quivering, eyes rolling, then she emitted a sudden yell, $\square \square \square \square \square \square$ (the author has deleted fifty characters). ${ }^{(5)}$

It is passages like this one that caused such a controversy upon the novel's publication.

Publicists and favourable critics drew immediate comparisons to The Plum in the Golden Vase (Jin ping mei 金瓶梅), the erotic masterwork of manners of the late Ming. Many others, however, registered disappointment if not disdain. Jia Pingwa had been previously acclaimed for his series of writings, both fictional and nonfictional, set in the rural region of Shangzhou in south-eastern Shaanxi, works that painted the simple and peaceful lives of villagers in the early reform years. Now, not only had he abandoned the countryside for the city, he had been co-opted by the latter's hedonism and consumerism, peddling pornography.

The charge of "selling out," frequently levelled at Jia Pingwa criticism, cannot be separated from the question of "serious literature" (yansu wenxue 严肃文学) and "popular literature" (tongsu wenxue 通俗文学) and their very bifurcation, an issue that was bound to escalate with Peking University's conferral in 1994 of an honorary professorship on Louis Cha, the author of wildly successful martial-arts fiction (wuxia xiaoshuo 武侠小说) published under the penname of jin Yong. ${ }^{(6)}$ It is no coincidence, then, that Decadent Capital contains two references to jin Yong. The plaints of Niu Yueqing, the wife of Zhuang Zhidie who operates a bookshop, reflect both the jin Yong vogue and the conditions of the book market:

Got a batch of Jin Yong's martial arts books. They sold well at first, but who would've thought that five bookshops would suddenly open on that street, all selling Jin Yong? Monkey see, monkey do. Now we're overstocked. ${ }^{(7)}$

Not long afterwards, an associate of Zhuang Zhidie's, Hong Jiang (洪江), suggests a scheme to market a martial arts novel written by "Quan Yong," the Chinese characters for Quan - 全 - and Jin - 金 - being similar. ${ }^{(8)}$ It is surely ironic that the businessman of letters - the very figure of lamentation and deprecation in criticisms of Jia - is variously incarnated in Decadent Capital. Besides Zhuang Zhidie there are three other eminent "cultural loafers" (wenhua xianren 文化闲人) in the city of Xijing (西京), or "western capital." The artist Wang Ximian (汪希眠) forges famous paintings and then spends the profits on women; the calligrapher Gong Jingyuan (龚靖元) sells his brushwork to fund a gambling habit; and this is how a friend of Zhuang's describes Ruan Zhifei (阮知非), the Qin opera performer turned leader of a song and dance troupe:

His performers are all contract workers; those that proper troupes don't dare to hire, he hires; the songs they don't dare to sing, he sings; the costumes they don't dare to wear, he wears. And so in the last five years they travelled all over the country, selling out every show, the money showering down like snowflakes. ${ }^{(9)}$

For Ruan Zhifei - as for the creator of Ruan Zhifei, so it seems - the breaking of taboos is what brings in the cash. The venerable arts of ages past, whether it be Chinese painting (guohua 国画), calligraphy, or Qin opera - or, if we are again to extend the comparison to Jia Pingwa himself, the classic Chinese novel - are not so much given up as retooled for more profitable purposes in the post-socialist era. Thus Hong Jiang advises Zhuang Zhidie on the secret to success:

Look at the times - it's very sensible for a literatus (wenren 文人) to do business. One's name is a source of wealth; you're wasting it if you're not using it. How can you get rich just by writing? One novella can't even trump a single character of Cong Jingyuan's. (...) Writing books can't beat selling books, and selling books can't beat compiling books. A lot of bookstores now compile their own books, either scoring a book number from a publisher or simply printing underground. All that they compile are little volumes of sex and murder, not even bothering with proofreading, print runs of hundreds of thousands of copies - raking in the dough! (10)

5. Jia Pingwa, Fei du (Decadent capital), Beijing, Beijing chubanshe, 1993, p. 85.

6. For more on this subject, see Chen Pingyuan, "Literature High and Low: 'Popular fiction' in twentieth-century China," in Michel Hockx (ed.), The Literary Field of Twentieth-Century China, Honolulu, University of Hawai'i Press, 1999, pp. 113-133. The debate on literary commercialisation began in the late 1980s over Wang Shuo and his best-selling "hooligan literature." See Wang Jing, "Wang Shuo: 'Pop Goes the Culture?"', in her High Culture Fever: Politics, Aesthetics, and Ideology in Deng's China, Berkeley, University of California Press, 1996, pp. 261-286.

7. Jia Pingwa, Fei du, op. cit., p. 73.

8. Ibid., p. 74.

9. Ibid., p. 14

10. Ibid., pp. 73-74. There is mention of another money-making writer of sex and violence later in the novel (ibid., p. 186). No book can be published in China without an International Standard Book Number (ISBN), which only the GAPP - now incorporated into the State Administration of Press, Publication, Radio, Film and Television (SAPPRFT) - can issue. Publishers submit a list of titles they plan to issue during a certain period of time and they are then given a block of ISBNs (Virginia Barry, Red - the New Black: China-UK Publishing, London, Arts Council England, 2007, p. 139). The 1980s saw the entrance into the publishing industry of "culture studios." Acting as literary agents in a sense, these unofficial, technically illegal publishers find an author, buy the rights to his or her work, then sell the title to an official publisher, with the culture studio and publisher sometimes sharing production costs, responsibilities for marketing and distribution, and of course profits (Mike Meyer, "The World's Biggest Book Market," The New York Times, 13 March 2005, www.nytimes.com/2005/03/13/books/review/013MEYERL.html [accessed on 12 May 2014]). Or the culture studio can simply buy a book number. Many state-owned publishing houses have trouble staying afloat in market conditions, and since a culture studio is allowed to prepare content for a publisher, it sells the publisher the rights to a work for a specified amount. The publisher then attaches an ISBN to it and sells it back to the culture studio in a separate contract and for a greater amount than the original sale. The difference is the cost of the ISBN (Virginia Barry, Red - the New Black, op. cit., pp. 81 and 89). The culture studio prints the title with the ISBN, and the book enters the market legally under the official publishing house's name. It is therefore difficult to assess how many culture studios exist, though estimates range from 5,000 to 10,000 (ibid., p. 87; The Economist, "Publishing mergers in China: A new binding," 23 May 2009, www.economist.com/node/13703892 [accessed on 12 May 2014]). 
Is this another instance of Jia's self-referentiality, and if so, to what extent does this playing point to his complicity? We will return to this question later in the article. Suffice it to say here that one could hardly find a more disheartening portrait in contemporary Chinese literature of the state of the culture industry. Decadent Capital's opening sentence identifies the setting as the 1980s, but the cynicism that drips from Hong Jiang's remarks above and the story as a whole is more in line with the novel's composition in the 1990s. For nowhere in the narrative is there a glimpse of the idealism associated with the decade that bridges the introduction of "reform and opening" (gaige kaifang 改革开放) in 1978 and the crushing of the 1989 protests. (11) Instead, intrigues, affairs, swindling, and bickering dominate the plotline. Given a cast of characters filled with the cultural elite, the total absence of discussions of aesthetics, current events, or social issues among them is revealing. It does not mean, of course, that jia offers no perceptive depictions of the profound shifts urbanites witnessed in the reform period, as the following vignette illustrates:

\section{Zhuang Zhidie turned into the street but didn't see a single banner on} display. The signs now read "ad headquarters" and "business card workshop." The residents already up were hanging sample ads on their stalls and storefronts. Puzzled, Zhuang Zhidie asked a fellow, "How come there's no one making banners on this street anymore?" The fellow said, "Don't you know the song 'Follow your feelings' (genzhe ganjue zou 跟着感觉走)? ${ }^{(12)}$ Back then the Communist Party was always holding meetings, and when there are meetings there have to be banners, and everybody on this street lived off those banners. Now the Party's all pragmatics and economics. The banner business slumped, but ad campaigns were launched everywhere, and people couldn't leave home without business cards. Who would've thought that with this change, our business is actually ten times better than before!" (13)

China's furious economic growth since reform is a well-worn headline in media reports East and West. What the above anecdote highlights, though, is the transition from one kind of publicness - which Jürgen Habermas would call "representative" (repräsentativ) - to another signalled by the replacement of banners by advertisements and business cards. ${ }^{(14)}$ The former display before the public the authority of the Party-state, while the latter vie for a public with power to purchase.

The passage above is also notable for another reason: it makes reference to the socialist era, one of the astoundingly few in the novel, which are always brief and glancing. ${ }^{(15)}$ Remnants of the era are reduced to artefacts as from an archaeological dig. A fan bearing the calligraphy of Kang Sheng, the Cultural Revolution's hatchet man, as well as a scroll of Mao Zedong's own calligraphy turn up. ${ }^{(16)}$ Yet they function precisely as antiques, objects to be treasured or traded, and no longer as talismans. Needless to say, the legacies of the socialist experiment persist in the People's Republic to this day. But within a framework that is decidedly post-socialist, Decadent Capital makes no mention of the former nationalisation of industry, collectivisation of agriculture, and communalisation of daily life. No spectre of Marx or Mao hovers over Xijing, no trace of the utopian program. It is as if that previous chapter of Chinese history that spanned approximately 30 years existed in some remote, curious past.

Herein lies jia's telling treatment of time. For in no way can we attribute it to short-sightedness. The "western capital" of Xijing is an obvious standin for Xi'an, the capital of many ancient dynasties (and the current capital of Shaanxi Province, where jia was born and continues to live and write). The novel resonates with innumerable echoes from the distant past, and vestiges of the glory days of a now "decadent capital" litter the diegetic décor: pieces of the crumbling city wall, rusted copper cash, centuries-old ink stones. ${ }^{(17)}$ The odour of decay is heavy and spreads from Xijing to elsewhere in the province, as Zhuang Zhidie relates:

Tongguan (潼关), my hometown, was historically the most important pass in Shaanxi's Guanzhong Plain, the setting of countless heroic tales. Ten years ago the county seat moved and the old walls fell into ruin. I went back to take a look not long ago and sat and sighed for half a day on the tower of the ruined wall. ${ }^{(18)}$

It is thus far from the case that the narrative lacks a historical frame of reference: the disintegration of the present is etched against a backdrop of former grandeur. The fate of the capital is mirrored in the fate of the characters, especially of the protagonist, all of whose relationships break down and who at the end tries to flee the city, only to die at the train station. There is no way out of this dystopia. Because of the parallel with Xijing/Xi'an's trajectory, the social, moral, and physical decline and degradation that unfold in the story seem inevitable, inescapable, immutable. That is why in 2009, on the occasion of the novel's republication, the author Ma Yuan (马原) said in an interview:

Thirty years ago, Chinese intellectuals (zhishi fenzi 知识分子) would be ashamed to talk about money, but by now l've seen so many writers bow and kneel down before power (quanli 权力) and money. More and more I see certain people around me becoming more and more like the Zhuang Zhidie type in Decadent Capital. ${ }^{(19)}$

A tale that supposedly takes place in the 1980s and was written in the 1990s rings no less true in the 2000s. As the logic of the market penetrates further into China's "creative industries" in the new millennium, the novel only seems to gain in prescience, no more so than when it is repackaged for sale 15 years after the original ban. But in his comments above, Ma Yuan slips in an element - "power, authority" (quanli 权力) - that is not readily apparent in the force field through which Zhuang Zhidie and his "cultural

11. Wang Jing sees the 1980 s as marked by both utopian fervour and impending crisis (High Culture Fever).

12. This immensely popular song appeared in Taiwanese singer Su Rui's 1988 album Taipei-Tokyo (Taibei Dongjing). Not counting bootlegs, it sold 800,000 licensed copies in China before getting banned after June Fourth (Nicholas D. Kristof, "A Taiwan Pop Singer Sways the Mainland," The New York Times, 19 February 1991, www.nytimes.com/1991/02/19/arts/a-taiwan-pop-singersways-the-mainland.html [accessed 8 April 2014]).

13. Jia Pingwa, Fei du, op. cit., pp. 346-7.

14. Habermas locates "representative publicness" in the body of the monarch and the manorial lord of the European Middle Ages (Jürgen Habermas, The Structural Transformation of the Public Sphere, translated by Thomas Burger, Cambridge, MIT Press, 1991, pp. 5-14).

15. Another can be found in the scene where Zhuang Zhidie's friend Zhao Jingwu speaks of how in 1950, Xijing's poor residents moved into the courtyard house (siheyuan) that his family owned, never to leave (Jia Pingwa, Fei du, op. cit., p. 44)

16. Ibid., p. 158.

17. For a penetrating examination of historical nostalgia in Decadent Capital, see Carlos Rojas, "Flies' Eyes, Mural Remnants, and Jia Pingwa's Perverse Nostalgia," positions: east asia cultures critique, Vol. 14, No. 3, 2006, pp. 749-773.

18. Jia Pingwa, Fei du, op. cit., p. 45

19. Li Pei, "Shi yu nian hou Fei du zaiban yin guanzhu" (After more than 10 years, Decadent capital's rerelease draws attention), Nanfang ribao, 30 July 2009, http://news.xinhuanet.com/book/200907/30/content_11796253_2.htm, (accessed on 5 April 2014). 


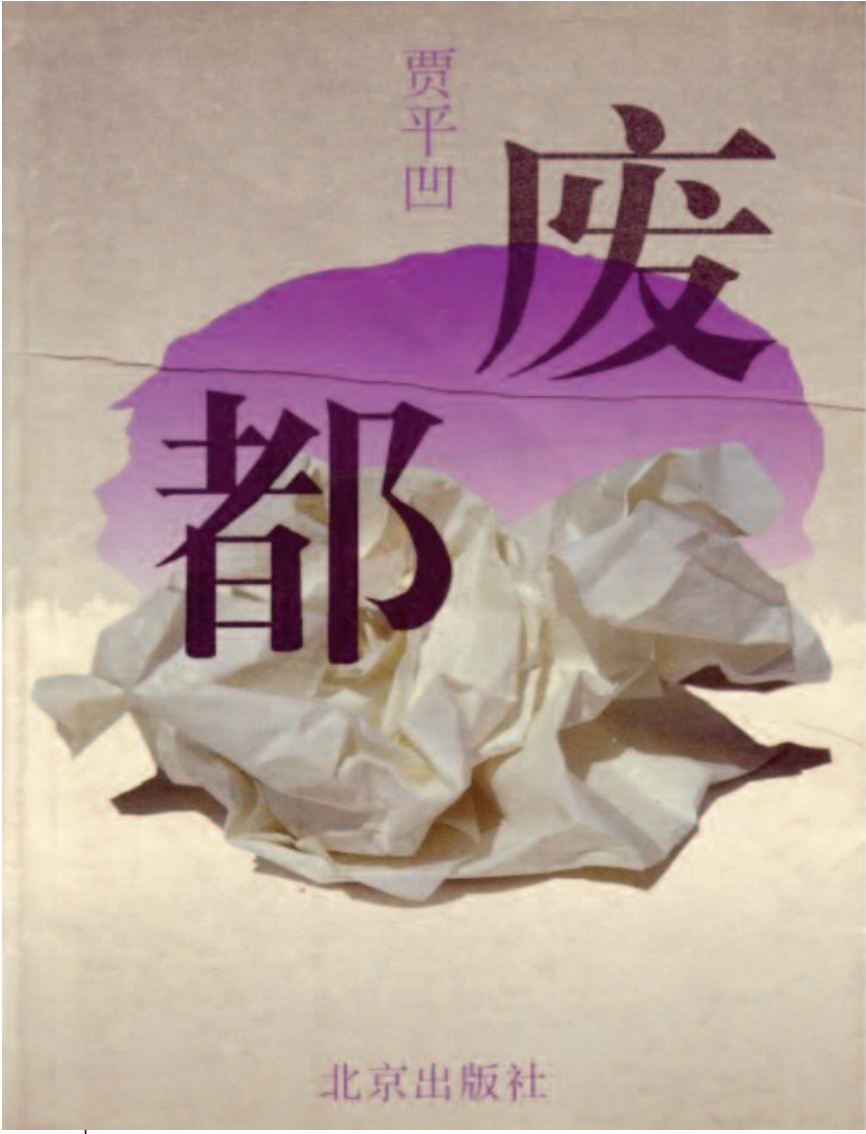

Image 1 - Front cover of the 1993 edition of Decadent Capital.

loafer" cohort move. The addition - power plus money - suggests that the book's re-release, aside from considerations of artistic vindication, has to be viewed in light of these twin vectors.

\section{The squares in question}

Perhaps to distance itself from the media circus surrounding the 1993 publication, the 2009 publisher, Writers Publishing House, did not hype the unbanning. In fact, Decadent Capital was reissued as part of a trio of new editions, safely in the middle, flanked by two untainted works, the 1987 Turbulence (Fuzao 浮躁) and the 2005 Qin Opera (Qinqiang 秦腔). One can surmise various reasons for the "rehabilitation:" the sex is no longer so shocking; or Jia Pingwa has in the meantime won the prestigious Mao Dun Literary Prize for Qin Opera; or those at the GAPP who handed down the ban are no longer there. In terms of the editions themselves, however, there are some concrete differences. The 1993 book features a rather dull cover with the characters Fei du in typescript and the centrepiece basically a crumpled sheet of paper with a purplish cloud in the background (Image 1). The colour design of the 2009 book, on the other hand, can be described only as hot pink (Image 2). In lieu of the mechanical title of 16 years ago, Jia's own dashing calligraphy runs down the cover. We are reminded that even the state-owned Writers Publishing House, run by the Chinese Writers Association - of which jia is a member - now has a division devoted to market assessment. ${ }^{(20)}$

Preceding each of the three novels in the new edition are three introductory essays by three esteemed literary critics: an editor at People's Literature

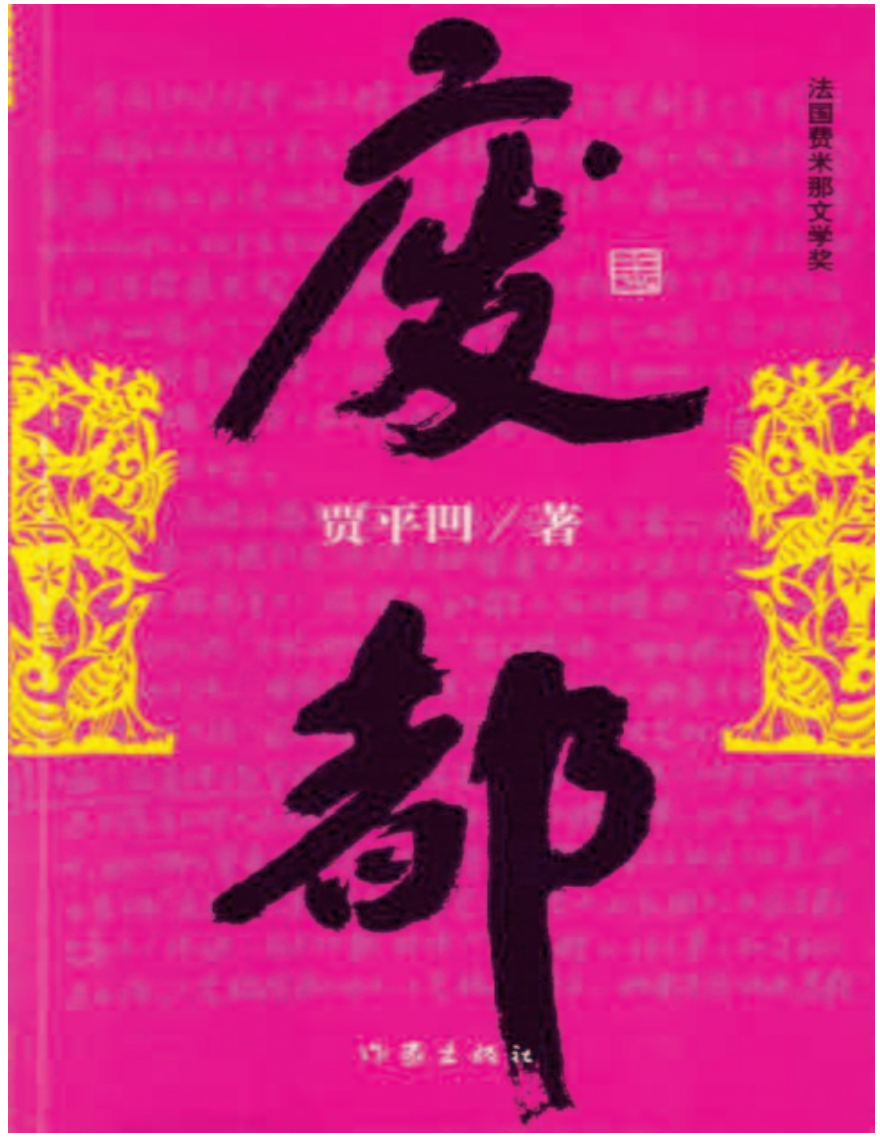

Image $\mathbf{2}$ - Front cover of the 2009 edition of Decadent Capital.

(Renmin wenxue 人民文学), Li Jingze, Peking University professor Chen Xiaoming, and Sun Yat-sen University professor Xie Youshun. (21) These essays no doubt serve to legitimise the republication of a work that was, in the words of the 1994 official ban, "low in character, mixed with pornographic descriptions" (gediao dixia, jiaza seqing miaoxie 格调低下, 夹杂色情描写). (22) Fifteen years later, the "pornographic descriptions" have remained intact. Not one character from the original has been removed, as the media liked to report. But there was change to the text. What Jia Pingwa had "self-censored" in 1993 was censored a second time, this time for good. In the 2009 edition the blank squares - $\square \square \square \square \square \square$ - were replaced by ellipses - ... ... . Replaced, too, was the count of deleted characters by "(here the author has made deletions)" (ci chu zuozhe you shan jie 此处作者有刪节). In some instances, the evidence of deletion was deleted altogether. ${ }^{(23)}$

20. Shuyu Kong, Consuming Literature: Best Sellers and the Commercialisation of Literary Production in Contemporary China, Stanford, Stanford University Press, 2008, p. 47. For the transformation of Writers Publishing House from essentially an in-house publisher for the Chinese Writers Association to a "best seller machine," see ibid., pp. 43-54.

21. Chen Xiaoming's considers Jia's oeuvre as a whole, while Xie Youshun's focuses on Qin Opera. I discuss Li Jingze's below.

22. Hao Jianguo,"'Shaan jun dongzheng' lushang de xing fengbo" (The sex crisis in the "Shaanxi army's eastern expedition"), Hua shangbao, 14 July 2008, http://hsb.hsw.cn/2008-07/14/ content_7030731.htm (accessed on 1 April 2014); Zhang Hong, "Jia Pingwa Fei du jiejin xinban shangjia" (Jia Pingwa's Decadent Capital unbanned, new edition for sale), Xin jing bao, 30 July 2009, http://culture.people.com.cn/GB/22219/9750476.html (accessed on 1 April 2014).

23. Compare, for example, Jia Pingwa, Fei du (Decadent capital), Beijing, Beijing chubanshe, 1993, p. 468, with jia Pingwa, Fei du (Decadent capital), Beijing, Zuojia chubanshe, 2009, p. 415. 
Li Jingze, author of the first prefatory essay in the new edition, "On Zhuang Zhidie" (Zhuang Zhidie lun 庄之蝶论), proposed the change. (24) This is how he partially justified the decision: "By drawing the blanks, he exhibited prohibition and at the same time transgressed the exhibited prohibition; indeed because of this he incurred censure, and it served him right." (25) The words that certainly jump out are the overbearing "served him right" (huogai 活该). This tone of criticism recalls certain initial reactions to the squares, which upon their appearance immediately became an object of fulmination in some quarters (not to mention titillation in others). One commentator from 1993, for example, similarly took the high road of finger-wagging:

...every ' $\square \square$ ' is a trap. Jia Pingwa wants adolescents to imagine things when they come across ' $\square \square$.' Jia Pingwa should suffer the rebuke of conscience. (26)

Youthful imagination should always be guarded against. Another commentator summons nationalist outrage, deeming Jia's squares "a false challenge of the censorship of publications intended to curry favour with readers in Hong Kong, Taiwan, and the West who are antipathetic to the institution of publishing in mainland China." (27) The following respondent, however, saw in them a relaxation of policy, the very transparency that Li jingze castigates: "...compared to that deletion method of 'cutting but not letting it be known whether it was cut or where it was cut,' this is certainly more open and respectful of the author and can be considered a kind of progress." (28)

To return to Li, he traces the provenance of the blanks to the bowdlerised editions of Ming and Qing erotic fiction. He does not, like commentators before him, accuse jia of arousing his readers' carnal fantasies, or even of commercialism. Rather, Li finds him guilty of shirking authorial responsibility:

I believe that the essential immorality (bu daode 不道德) of those " $\square \square \square$ " is this kind of sneaking away by Zhuang Zhidie, this kind of irresponsibility. Jia Pingwa strongly felt that he was powerless to touch, imagine, and describe certain things inside this character's mind and body; he could not make Zhuang Zhidie bear definite personal responsibility for his actions, including moral (daode 道德) and ethical (lunli 伦理) responsibility. And so he cleverly performed a masterful manoeuvre, gathering ghosts of the past, rendering this person absent. ${ }^{(29)}$

Li Jingze wants Zhuang Zhidie to stay in place, punished for his immoral behaviour with lifelong imprisonment in the dystopian diegesis. Zhuang might pay with his life at the end, but death is an insufficient finality. That is why Li, in the re-authorised edition, assumes the responsibility of removing those blank squares, closing the doors through which Zhuang - and Jia Pingwa - can abscond. And this time the intervention comes not from the GAPP but from within, as it were, from an editor, a critic, a colleague.

Li's verdict appears to be diametrically opposed to the position argued below by a commentator in 1993. Both criticise the blank squares, but far from allowing protagonist and author to escape, they are like walls that ultimately prevent the reader from entering, ruling out any input, as this extended excerpt asserts:

The most eye-catching and commented-upon thing in Decadent Capital is " $\square \square \square \square \square$ (the author deleted xx characters)." This device of course is the affectation and pretence of fear and respect toward social prohibition (shehui jinji 社会禁忌) and discursive power (huayu quanli 话语权力). It obviously imitates the cultural apparatus (wenhua jiqi 文化机器) that deletes text to guarantee that the rules of discourse are not broken. But the contradiction here is that the original deletions of sections of text that overstep discursive limits rest upon the existence of an undeleted "original" (diben 底本), and the existence of this original edition is taken for granted by everyone (such as the expurgated Plum in the Colden Vase); it is simply that the norms of discourse have erased and wiped it clean. But jia Pingwa has bestowed upon the "author" (zuozhe 作者) a double identity. The one expurgating here is not the cultural apparatus but the "author." "Author" and "expurgator" have bizarrely become one: writing and deleting parallel each other. Any reader confronting this infinitely reproduced (wuqiong fuzhi 无穷复制) text will discover that he or she has not the slightest chance or possibility of filling in those " $\square \square \square \square \square$." These deletions play with (xishua 戏要) - and strongly entice - the reader. Jia Pingwa uses this method to suppress the author's authority (quanwei 权威) even as he reforges that authority another way. For no reader's imagination can ever solve the riddles; no reader can discuss equally these abstruse deletions with the author. Thus, the fabricated deletions become the token (biaoji 表记) and code (daima 代码) of this style, the most enticing in the story of Zhuang Zhidie. This is also a token and code moving towards consumption and the market. ${ }^{(30)}$

Whereas Li Jingze, in securing Zhuang Zhidie within the text, locks himself in as well, this commentator treats the blank squares as an interface oriented towards the reader/consumer, whom they do not merely entice. Rather, they are a tease, a consummate commodity that beckons but never satisfies. The foresight of this reading is remarkable, for we could say it pertains less to the 1993 than to the 2009 edition. It is in the new Decadent Capital that we find the barefaced reassertion of authority, intoned from the intellectual high ground of a backward-gazing prefatory essay, along with the shedding of all accountability. Both the squares and the count of deleted characters have been removed, nullifying any ability on the part of readers to "discuss equally" (pingdeng di taolun 平等地讨论). Order has been restored, as the roles of not only author and expurgator but also of producer and consumer are once again fixed.

We have learned from Jia's subsequent interviews the story behind those blank squares - $\square \square \square \square \square \square$ - followed by "(the author has deleted $n$ characters)." (31) He did not write out the sex scenes completely, knowing they would never see the light of day, and in revision he made some further deletions. Then the editor made some more, and jia added the blanks and the

24. Zhang Hong, "Jia Pingwa Fei du jiejin xinban shangjia," art. cit.

25. Li Jingze, "Zhuang Zhidie lun" (On Zhuang Zhidie), in Jia Pingwa, Fei du, Beijing, Zuojia chubanshe, 2009, p. 1.

26. Xiao Xialin (ed.), Fei du fei shei, op. cit., p. 140.

27. Duo Wei (ed.), Fei du ziwei (Taste of Decadent Capital), Zhengzhou, Henan renmin chubanshe, 1993, p. 155

28. Ibid., p. 152

29. Li Jingze, "Zhuang Zhidie lun," art. cit., p. 2.

30. Xiao Xialin (ed.), Fei du fei shei, op. cit., p. 236.

31. Zha Jianying, China Pop: How Soap Operas, Tabloids, and Bestsellers Are Transforming a Culture, New York, New Press, 1995, p. 149; Hao Jianguo, "'Shaan jun dongzheng' lushang de xing fengbo," art. cit. 
number of deleted characters. The " $n$," therefore, does not correspond to the actual number of characters taken out. ${ }^{(32)}$

May we then conclude that Li Jingze's editing constitutes a rectification? The story of Decadent Capital, from 1993 to 2009, has not changed in the slightest, as the publisher and reviewers are fain to point out. After causing so much controversy, after provoking so much rebuke, have the blank squares - tiny price tags on our lecherous thoughts, little escape hatches for our weaker selves - been finally, legitimately effaced? After all, the novel has now been proofread for the erroneous and the extraneous: the count was a sham, and the blanks had nothing there.

\section{Reconstituting the public}

This is not the first time that blank squares have appeared in modern Chinese critical discourse. In May 1934, in "More on '...... " $\square \square \square \square$ "' (“......" $\square \square \square \square$ "lun bu 论补), written under the pseudonym Man Xue (曼 雪), Lu Xun humorously remarked that "......" is foreign, imported, and (according to him) post-May Fourth, while blank squares are "domestic products" (guohuo 国货). ${ }^{(33)}$ He had in mind ancient writings on bamboo strips whose missing or indecipherable characters are transcribed as $\square$ 's. He was responding to a piece called "On「 「.............. 「 $\square \square \square \square \square\rfloor$ " ( 「..... ......... 「 $\square \square \square \square \square\rfloor$ lun 论), published earlier in the month by the writer Xu Xu (徐訏) in the bimonthly journal that features the style of the "short informal essay" (xiaopinwen 小品文), In the Human World (Ren jian shi 人间世), where Xu was also an editor (the chief editor was Lin Yutang 林 语堂). As Xu declares in this piece, "The fact that ' $\square \square \square \square^{\prime \prime}$............' are already commonly encountered in the news in newspapers and the telegrams of important personages is already a problem encountered by everyone." (34) For $\mathrm{Xu}$, the blank squares evince a reluctance or inability to say - due to mental laziness or cowardice - what ought to be said. It is a problem affecting all of society, and he lauds scientists such as Darwin, for example, for daring to say - that we come from apes - what others dare not, and writers who are able to describe what readers cannot find words for.

Lu Xun was critical of the "short informal essay" style (and of Lin Yutang, who championed it). ${ }^{(35)}$ In his response, he follows Xu in deploring the appearance of blank squares in contemporary publications. But the reasons he gives are quite different. It is a phenomenon, Lu Xun says, that makes two sets of people happy: the government censor, who sees that his work is done for him, and the reader, who is aroused by the fill-in-the-blank squares. He believes it to be a kind of commercial deception, the selling of something not there:

Nowadays all things have to be bought with money, and so naturally all things can be sold for money. But the fact that even "nothing" can be sold for money is rather beyond expectation. Once you know this, however, you then understand that rumour-mongering can now be considered an "honest way" to make a living. ${ }^{(36)}$

The encroachment of capitalist ethics into the cultural and intellectual domains, especially in Shanghai, where Lu Xun lived at the time, certainly perturbed him. ${ }^{(37)}$ A mere six months after the response above, however, Lu Xun was assessing the blank squares differently. In "The demons of the Chinese literary scene" (Zhongguo wentan shang de guimei 中国文坛上的鬼鬼) of November 1934, he observed that Nationalist government censors no longer allowed authors to leave blanks in place of words struck out. ${ }^{(38)} \mathrm{He}$ also brought up the system of pre-publication censorship instituted that June after a meet- ing in Shanghai between the authorities and publishers. ${ }^{(39)}$ It was becoming clear that blank squares resisted rather than assisted the work of censorship.

Perhaps he remembered a blank square in his own fiction. It appears in "Medicine" (yao 药), published in New Youth (Xin qingnian 新青年) in May 1919. Old Shuan, believing it will cure his consumptive boy, buys a steamed bun soaked in blood, which, we learn, was spilled from a revolutionary just executed. Near where Old Shuan makes the purchase is a place called Ancient Blank Ting Kou. ${ }^{\left({ }^{40)}\right)}$ As the editors of Lu Xun's Complete Works tell us, this is an allusion to the martyrdom of the famed revolutionary Qiu jin, killed by Qing troops in July 1907 at a place called Xuan Ting Kou in Lu Xun's hometown of Shaoxing. (41) In the story, then, the character xuan (轩) is replaced by a blank square.

We do not know who was responsible for this, whether Lu Xun himself sketched the square in the manuscript. But we do know that, whatever the case, the little square serves as a kind of post-it note to remind readers of someone no longer there, or - to use another metaphor - a blank memorial tablet erected right there on the page for a past event that still could not be written about directly. In "Medicine," as in Decadent Capital, the blank square performs censorship, revealing it as a force that does not merely come down at the end to cut or cross out but one that is present from the beginning, constitutive of writing itself. Like Lu Xun before him, Jia Pingwa writes through censorship, his work not so much marred by it as formed with it. What separates Jia's novel is its 1994 ban. In his case, therefore, the target was not only certain contents of the book but the book in its entirety. The ban drove its public underground, and though the pirate economy kept it alive - twelve million copies, official and bootleg, have supposedly been sold - reception became technically an illicit undertaking. ${ }^{(42)}$ Gone were all public discussions of the novel.

32. At the time of publication, however, myths of an original, unexpurgated edition circulated - as well as pirated "unexpurgated editions" themselves with the blanks filled in, so to speak.

33. Lu Xun, Lu Xun quanji (Complete works of Lu Xun), Vol. 5, Beijing, Renmin wenxue chubanshe, 2005 , p. 511. Lu Xun also observes that more and more " $x$ " can be found in publications, which, he says, is something imported from Japan.

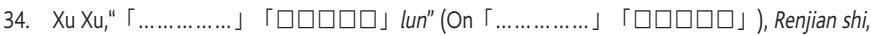
Vol. 4, 20 May 1934, p. 21.

35. See Lu Xun's "Lunyu yinian" ("A year of The Analects") and "Xiaopinwen de weiji" (The crisis of the short informal essay) in Lu Xun, Lu Xun quanji, Vol. 4, op. cit., pp. 582-593.

36. Lu Xun, Lu Xun quanji, Vol. 5, op. cit., p. 512.

37. The quintessential tale of Shanghai industrial and financial capitalism in the $1930 \mathrm{~s}$ is, of course, Mao Dun's 1933 Midnight (Ziye). For an overview and critique of scholarship on commerce and culture in republican Shanghai, see Wen-hsin Yeh, "Shanghai Modernity: Commerce and Culture in a Republican City," The China Quarterly, Vol. 150, 1997, pp. 375-394.

38. Lu Xun, Lu Xun quanji, Vol. 6, op. cit., p. 162. We may recall that, in the massive editing of books for collection in the Qing Emperor Qianlong's The Emperor's Four Treasuries (Siku quanshu), offending characters and sections had to be replaced with other characters; no blanks could remain (R. Kent. Guy, The Emperor's Four Treasuries: Scholars and the State in the late Chien-lung Era, Cambridge, Harvard University Press, 1987, p. 193).

39. Ibid., p. 161. Blanks are touched on again a year later in "Preface to Decorative Literature" of December 1935: "1934 was not like 1935. This year, because of the 'Chitter Chatter Emperor' incident, the press and publication censorship department was at a loss. It even fired seven censors, and it appears that newspapers could keep blank what was deleted (the technical term is 'open a skylight')" (Lu Xun, Lu Xun quanji,Vol. 5, op. cit., p. 438). As an editorial note explains, "Chitter Chatter Emperor," published in May 1935 in the Shanghai-based Xin sheng (New Life), criticised the institution of monarchy in reference to the Japanese emperor. In part to appease Japan and in part to suppress "progressive" opinion, Nationalist authorities shut down the weekly and sentenced the editor-in-chief to 14 months in prison (Ibid., p. 440)

40. Lu Xun, Lu Xun quanji, Vol. 1, op. cit., p. 465.

41. Ibid., p. 472.

42. Di Ruihong, "Fei du jiejin Jia Pingwa: wei ta yi tong shiqi nian" (Decadent Capital unbanned: Jia Pingwa's 17-year pain), Hua shangbao, 28 July 2009, http://hsb.hsw.cn/200907/28/content_7404550.htm (accessed on 1 April 2014). The novel's clandestine lives began even before it could no longer be legally printed, circulating in various pirated editions. Jia said in an interview that he has over 70 pirated versions in his collection (Mu Tao, "Lüli" [Curriculum vitae], Dangdai zuojia pinglun, No. 5, 2005, p. 27) 
In many ways, Decadent Capital enacts censorship's vitiation of the public as well. Absent from the narrative is anything resembling a public realm in the strong sense. Corruption is prevalent from the press to the judicial system: newspaper articles are all paid for, and judges are open to influence. ${ }^{(43)}$ The government is no different. Zhuang Zhidie seeks to win favour for the lawsuit that embroils him by marrying his pretty housemaid to the mayor of Xijing's handicapped son. Although politics at the national level are not depicted, Zhuang does imply that they simply replicate the local: "A Central Politburo meeting is probably like this, too: a few people talk it over at someone's home, and a state policy is settled." (44) Behind their public façades, these institutions are driven by private dealings. The following is a rumination - coming from the consciousness of a cow from whose teats Zhuang Zhidie drinks milk directly - on the lack of anything truly collective in the city's public life:

What makes man, from the harmony and love of a village or hamlet where everyone knows everyone's grandfather's pet name and whose chicken is running around, come to a city where each family has its own unit and you close the door as soon as you've entered and suddenly nobody acknowledges anybody? So many people on the streets - I breathe in the air you breathe out, you breathe in the air I breathe out - people crowded on buses, crammed into theatres, but they stare without knowing one another. Like sand, you can grab a handful; when you let go, the grains come apart. Add water and they drift apart even further! (45)

The city should be the site of the public, yet the passage, with familiar tropes of alienation despite population, presents its ostensible absence: even when people gather in the public space of a bus or theatre, they do not constitute a community sharing something in common. What the rest of the novel illustrates, however, is the exact opposite of strangers. Residents of Xijing know each other only too well. Far from separating like sand, they are inextricably entangled in a bog of relationships. If there is nevertheless no public, it is due not to the urban as such but precisely to its ruralisation. The intimacy of village life is transplanted onto the dynamics of a city. It is not that people do not speak to one another. They talk too familiarly, unable to put aside their private interests, mutual or conflictual, for any broader horizon.

Herein lies the danger of Jia Pingwa's performance of censorship. I disagree with one critic who believes the blank squares represent only a "minor technique": "That the author of Decadent Capital uses this manoeuvre to parody the 'cleaning' of texts is indeed innovative, but it is a pity that this kind of parody of previous texts is only a minor technique in Decadent Capital; it does not develop into the attitude of the entire text." (46) Parodic reflexivity, as the "cultural loafers" illustrate, is indeed characteristic of the work as a whole. But to what extent is Jia complicit in the very things he pokes fun at? Is he critiquing the man of letters who opts for lucre, or is he profiting from his very portrayal? And more importantly, is his playing a mere reproduction of the effects of censorship without offering a way out? Just as the Chinese state, ever since the 1989 protests that centred on a public square, has aimed to close alternative publics, so too does Decadent Capital seemingly represent no alternatives. Though Jia cannot be accused of glorifying the venal characters in his novel, as testified by their deplorable outcomes, Zhuang Zhidie's failed escape and ultimate demise, not to mention his inability to finish the novel he is working on, might simply mirror the impasse facing an author writing in post-Tiananmen China. This is the threat of constitutive censorship. The blank squares, as well as the narrative itself, reenact the impairment and perversion of the public.

As shown earlier, when the novel was published in 1993, many commentators aired their stance on those squares, as if to compensate for not standing on another square that had been cleared four years previously. In fact, through debating Decadent Capital, Chinese intellectuals, quieted if not silenced since the military crackdown on public demonstrations in 1989 and the general clampdown on public discussions afterwards, found their voices again. ${ }^{(47)}$ Riding on the industry in the book was another albeit much smaller industry in its commentary, as evidenced by these titles, all from 1993: What's wrong with Jia Pingwa (Jia Pingwa zenme la 贾平凹怎么啦), Decadent Capital, decadent who? (Fei du fei shei 《废都》废谁), Taste of Decadent Capital (Fei du ziwei 《废都》滋味), Decadent Capital and "Decadent Capital Fever" (Fei du yu "Fei du re" 《废都》与“废都热”), Riddle of Decadent Capital (Fei du zhi mi 《废都》之谜), and Decadent Capital, Oh Decadent Capital (Fei du a Fei du 《废都》啊, 《废都》). The novel may not have portrayed any publics, but it did bring them about, both reading publics and critical publics in the press and periodicals.

These publics were, of course, shut down upon the 1994 ban. With the 2009 unbanning and their being allowed once again to assemble openly, what is needed, then, is a reassessment of Jia Pingwa's performance of censorship, especially his blank squares, in light of the new edition, which confirms that they were and have always been the most offensive aspect of the novel. Their banishment, whether one regards it as a distortion or a revision, calls for a critical retort, by which I do not intend a return. I have no office to restore the squares, or to carry out a recount of the "deleted characters." Yet re-viewing the text is a gesture I fully own, the one response left to a reader who can only figuratively re-place the replaced. My objective consists in both a public-making of censorship - "exhibiting prohibition" - and a public-making against censorship, the re-summoning of a dispersed aggregate.

Every blank in Decadent Capital is an ou-topos, a not-place inserted to say no to the engulfing dystopia that appears all but ineluctable. This outopos is not also an ou-chronos. it is not beyond time but precisely a threshold for time to flow over and wash over the seeming permanence of a demoralised and disillusioned, post-(Tiananmen, socialist, golden age) present. The blank squares open not only onto a future unforeclosed but also into an elided past. We will recall that the narrative manifests hardly any recollection of the socialist epoch. Curiously enough, it also contains an admonition against man's historical amnesia, coming again from the milk cow:

The cow really wants to tell humans about the past, but it's a pity that the cow doesn't speak human. So when time and again humans forget the past and, after things have passed, flip through threadbound annals, sighing "the shockingly familiar in history," the cow scoffs in his heart at the pathetic humans. ${ }^{(48)}$

43. Jia Pingwa, Fei du, op. cit., pp. 131-132

44. Ibid., p. 277

45. Ibid., p. 141

46. Xiao Xialin (ed.), Fei du fei shei, op. cit., p. 146.

47. A concomitant debate that fed on and into the controversy surrounding Decadent Capital is expounded in the authoritative chapter "Ideologies of Popular Culture: The 'Humanist Spirit' Debate," in Jason McGrath, Postsocialist Modernity: Chinese Cinema, Literature, and Criticism in the Market Age, Stanford, Stanford University Press, 2008, pp. 25-58.

48. Jia Pingwa, Fei du, op. cit., p. 140. 
The story, we will remember, is ostensibly set in the 1980s, which makes the socialist epoch its immediate past. We will also remember that the novel was written in the early 1990s, which makes the 1989 movement its immediate past. Both of these immediate pasts are glaringly missing from Decadent Capital. Jia Pingwa's "forgetting" of them enacts his characters' as well as his contemporaries' short-term memory loss in their headlong rush for riches and turn-ons. But it is more than a forgetting. The blank squares are emblems of the censorship that enforced omission. They stand in, then, for the recurring ou-topos - the not-place and not-motif - that is Tiananmen Square. In this way does a graphic hiatus - $\square \square \square \square$ - represent a historiographic one.

Objections will no doubt be raised that I am twisting Jia's blanks, which we all know signify sex too hot to print, without the "philosophy." (49) Decadent Capital may have been written four years after the protests, but there is not the least hint of them, or of national events and debates on social ills. If there is politics in the narrative, it is the politics of one-upsmanship: the calculation of interests, the exchange of favours, and the jockeying for advantage in the web of desire.

That could have been argued at one point in time. But with the censorship of the squares in 2009, 16 years after the novel's first appearance and 20 years after Tiananmen, what has become clear is that the challenge they pose lies in their alternative publicness. To substitute ellipses for blank squares is to blot out the former's receptivity. Those little squares, meas- uring no more than a few square millimetres on the page, are windows to worlds of meaning as well as yearning. And they were closed, shrunken to the true void - as opposed to the blank - that is the black dot, neither because they were some "token and code moving towards consumption and the market" - the state-mandated direction for decades - nor because they let the author shirk responsibility for what he wrote, but because they called on the reading public for a reengagement and response not predetermined. They pointed forwards to the myriad possible ways of filling them, and backwards too, designating the open space of a public square on which people had collected one late spring, functioning as visual cues or bookmarks holding the place in the pages of history. That is why the 2009 re-release is not so much a loosening of censorship, or even industry trumping ideology, as a repackaging of strategy to shape the public. The blank squares could not be allowed to rest in peace underground. The banned book had to be brought back to life, only to be subjected to another violence, the clearing of its squares a re-enactment of what happened on a June night, those ellipses without count like so many bullets echoing in the dark.

\section{Thomas Chen is a PhD candidate in Comparative Literature at the} University of California, Los Angeles.

350 Humanities Building, Box 951536, Los Angeles, CA 900951536, USA (tchen6@ucla.edu). 